\title{
The Impact of Lung Function on Extra-Pulmonary Diseases and All-Cause Mortality in US Adult Population with and without COPD
}

This article was published in the following Dove Press journal: Clinical Epidemiology

\author{
Kai Yang $\mathbb{D}^{1, *}$ \\ Ying $\mathrm{Wu}^{2, *}$ \\ Dandan Chen' \\ Shengming $\mathrm{Liu}^{3}$ \\ Rongchang Chen'
}

'Shenzhen Institute of Respiratory Diseases, Shenzhen People's Hospital (The Second Clinical Medical College, Jinan University, The First Affiliated Hospital, Southern University of Science and Technology), Shenzhen, Guangdong, People's Republic of China; ${ }^{2}$ Department of Biostatistics, School of Public Health, Southern Medical University, Guangzhou, Guangdong, People's Republic of China; ${ }^{3}$ Department of Respiratory Medicine, The First Affiliated Hospital, Jinan University, Guangzhou, Guangdong, People's Republic of China

*These authors contributed equally to this work
Correspondence: Rongchang Chen Shenzhen Institute of Respiratory Diseases, Shenzhen People's Hospital (The Second Clinical Medical College, Jinan University, The First Affiliated Hospital, Southern University of Science and Technology), Shenzhen 518055,

People's Republic of China

Email chenrc@vip.I63.com

Shengming Liu

Department of Respiratory Medicine, The First Affiliated Hospital, Jinan University, Guangzhou 510000, People's Republic of China

Email tlsm@jnu.edu.cn
Objective: Spirometric lung function is usually used to evaluate respiratory health. However, the impact of lung function on extra-pulmonary diseases and all-cause mortality has not been fully elucidated, especially in people without chronic obstructive pulmonary disease (COPD).

Patients and Methods: Participants aged $\geq 20$ and underwent spirometry test from the US National Health and Nutrition Examination Surveys (NHANES) 2007-2012 were analyzed in this study. Multivariate logistic and Cox regressions were used to evaluate the impact of forced expiratory volume in 1 second percent of predicted ( $\mathrm{FEV}_{1} \%$ predicted) and forced vital capacity percent of predicted (FVC\% predicted) on 14 extra-pulmonary diseases and all-cause morbidity after adjusting for multiple confounders.

Results: During 2007-2012, 1800 COPD patients and 11,437 non-COPD subjects were included. The prevalence of hypertension, diabetes mellitus (DM), dyslipidemia, metabolic syndrome (MS), congestive heart failure (CHF), coronary disease, stroke, chronic kidney disease (CKD), arthritis, cancer, underweight and osteoporosis in COPD patients was higher than that in the non-COPD population. After adjusting for confounders, the decrease of $\mathrm{FEV}_{1}$ $\%$ predicted and $\mathrm{FVC} \%$ predicted was related with higher odds of having hypertension, DM, obesity, MS, CHF, coronary disease and depression (OR $>1, P<0.05)$ in both the COPD and non-COPD populations. These 2 indices were also related with higher odds of dyslipidemia, CKD, arthritis and osteoporosis in the non-COPD population. The risk of stroke, anemia and cancer was not related with the decrease of lung function. In addition, the decrease of lung function was independent risk factors for the increase of all-cause mortality. These risks were gradually increased with the decrease of lung function.

Conclusion: The decrease of $\mathrm{FEV}_{1} \%$ predicted and $\mathrm{FVC} \%$ predicted was related with higher risk of multiple extra-pulmonary diseases and all-cause mortality in both the COPD and non-COPD population.

Keywords: lung function, mortality, extra-pulmonary diseases, COPD

\section{Introduction}

Spirometric lung function is usually used to evaluate respiratory health and diagnose pulmonary disease, such as chronic obstructive pulmonary disease (COPD), asthma and small airway disease. ${ }^{1,2}$ Forced expiratory volume in 1 second percent of predicted ( $\mathrm{FEV}_{1} \%$ predicted), forced vital capacity percent of predicted ( $\mathrm{FVC} \%$ predicted), and $\mathrm{FEV}_{1} / \mathrm{FVC}$ ratio are most commonly used indices of lung function, which can be used to define COPD and evaluate the severity of airflow limitation 
and lung injury. ${ }^{3}$ In addition to the impact on respiratory health, there is increasing evidence that COPD is associated with morbidity and mortality of some extrapulmonary diseases. ${ }^{4-7}$ However, limited research has focused on the influence and its extent of lung function on these diseases and morbidity in the population with normal lung function compared with COPD patients.

COPD often coexists with one or more comorbidities, which can contribute to poor health quality, healthcare costs and morbidity of patients. ${ }^{3,8,9}$ The comorbidities reported in previous studies mainly included cardiovascular disease, hypertension, diabetes mellitus (DM), lung cancer, osteoporosis, anxiety and depression, which may be caused independently by COPD or share similar risk factors with COPD. ${ }^{3,10,11}$ Lung function impairment is the most important characteristic of COPD, which indicates that the decrease of lung function indices may mediate the impact of COPD on comorbidities and morbidity. ${ }^{12,13}$

$\mathrm{FEV}_{1} / \mathrm{FVC}$ is usually used to define COPD, while $\mathrm{FEV}_{1} \%$ predicted and $\mathrm{FVC} \%$ predicted have higher correlations with severity of lung injury. ${ }^{14,15}$ Therefore, the main purpose of this study was to determine whether the decrease of $\mathrm{FEV}_{1} \%$ predicted and $\mathrm{FVC} \%$ predicted are associated with the prevalence of 14 extra-pulmonary diseases and morbidity in both the COPD and non-COPD populations after adjusting for potential confounders. We also aimed to evaluate the extent to which the decrease of lung function impacts these diseases and morbidity.

\section{Patients and Methods}

\section{Data Source}

Data from 3 cycles of the National Health and Nutrition Examination Survey (NHANES) spanning 2007-2012 were used in this study, which were released by the Centers for Disease Control and Prevention (CDC). Demographic data, spirometry test, disease information, dietary data, and laboratory and questionnaire data related with disease definition were extracted and combined from different NHANES files. Mortality status and follow-up time for all subjects were extracted from the National Death Index by 31 December 2015. Among the 30,442 subjects in 3 cycles, we included 13,237 subjects $(6,679$ men and 6,558 un-pregnant women) for further analysis, who were aged $\geq 20$ and underwent spirometry test. Further details about NHANES were introduced in the Supplementary Method. All the data in this study were freely available on the NHANES homepage (http://www. cdc.gov/nchs/nhanes.htm), which was approved by the National Center for Health Statistics Institutional Review Board of the CDC. Ethical approval was not required for this study.

\section{Spirometry Test and COPD}

Spirometry test was offered to subjects during NHANES 2007-2012 who meet certain inclusion criteria. Due to the lack of post-bronchodilator spirometry test for most subjects, COPD was defined as pre-bronchodilator $\mathrm{FEV}_{1} / \mathrm{FVC}$ $<0.7$, which was different from the Global initiative for the management of chronic Obstructive Lung Disease definition. ${ }^{3}$ Predicted $\mathrm{FEV}_{1}$ and FVC were calculated according to the equations of Hankinson et al considering race, gender, age and height. ${ }^{16} \mathrm{FEV}_{1} \%$ predicted was divided into 5 groups in the COPD population: $\mathrm{FEV}_{1}<$ $60 \%$ predicted, $\mathrm{FEV}_{1} 60 \% \sim 70 \%$ predicted, $\mathrm{FEV}_{1} 70 \% \sim$ $80 \%$ predicted, $\mathrm{FEV}_{1} 80 \% \sim 90 \%$ predicted, and $\mathrm{FEV}_{1} \geq$ $90 \%$ predicted, and 4 groups in the non-COPD population: $\mathrm{FEV}_{1}<80 \%$ predicted, $\mathrm{FEV}_{1} 80 \% \sim 90 \%$ predicted, $\mathrm{FEV}_{1}$ $90 \% \sim 100 \%$ predicted, and $\mathrm{FEV}_{1} \geq 100 \%$ predicted. FVC $\%$ predicted was divided into 4 groups in both the COPD and non-COPD populations: FVC $<80 \%$ predicted, FVC $80 \% \sim 90 \%$ predicted, FVC 90\% 100\% predicted, and $\mathrm{FVC} \geq 100 \%$ predicted.

\section{Definition of Diseases}

In this study, we analyzed the impact of lung function on 14 extra-pulmonary diseases. Three lung diseases (asthma, chronic bronchitis and emphysema) were analyzed as confounding factors. The definition of these diseases were as follows:

Hypertension was defined as a systolic blood pressure $(\mathrm{SBP}) \geq 140 \mathrm{mmHg}$, a diastolic blood pressure (DBP) $\geq 90$ $\mathrm{mmHg}$, a self-reported physician diagnosis of hypertension, or a use of anti-hypertensive medications. SBP and DBP were the average of 1 to 3 blood pressure measurements. ${ }^{17}$

DM was defined as a fasting plasma glucose $\geq 126 \mathrm{mg} /$ $\mathrm{dL}$, a glycated haemoglobin $\geq 6.5 \%$, 2-hour glucose of Oral Glucose Tolerance Test $\geq 200 \mathrm{mg} / \mathrm{dL}$, a self-reported physician diagnosis of DM, a use of glucose-lowering medications, or a use of insulin injections. ${ }^{18}$

Obesity was defined as body mass index (BMI) $\geq$ $30 \mathrm{~kg} / \mathrm{m}^{2}$, overweight was defined as $25 \mathrm{~kg} / \mathrm{m}^{2} \leq$ BMI $<$ $30 \mathrm{~kg} / \mathrm{m}^{2}$, and underweight was defined as BMI $<18.5 \mathrm{~kg} /$ $\mathrm{m}^{2}$, according to the CDC guidelines. ${ }^{19}$ 
Table I Baseline Characteristics of Subjects With and Without COPD

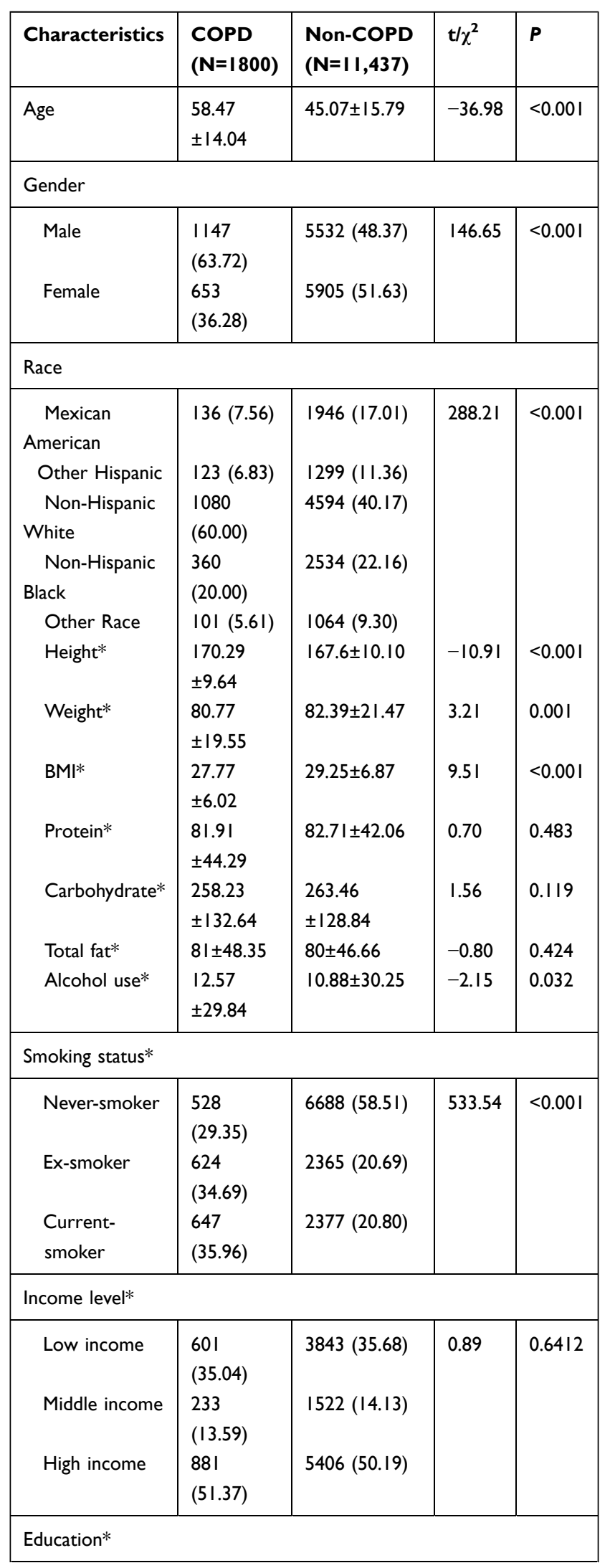

(Continued)
Table I (Continued).

\begin{tabular}{|c|c|c|c|c|}
\hline Characteristics & $\begin{array}{l}\text { COPD } \\
(\mathrm{N}=1800)\end{array}$ & $\begin{array}{l}\text { Non-COPD } \\
(N=I \mid, 437)\end{array}$ & $t / \chi^{2}$ & $P$ \\
\hline$<$ High school & $\begin{array}{l}522 \\
(29.02)\end{array}$ & 2845 (24.89) & 36.49 & $<0.001$ \\
\hline $\begin{array}{l}\text { High school } \\
\text { or equivalent }\end{array}$ & $\begin{array}{l}465 \\
(25.85)\end{array}$ & $2550(22.31)$ & & \\
\hline$>$ High school & $\begin{array}{l}812 \\
(45.14)\end{array}$ & $6033(52.79)$ & & \\
\hline Mortality* & $\begin{array}{l}180 \\
(10.01)\end{array}$ & $382(3.35)$ & $169.5 \mid$ & $<0.001$ \\
\hline FEV & $2.43 \pm 0.83$ & $3.14 \pm 0.88$ & 33.15 & $<0.001$ \\
\hline FVC & $3.83 \pm 1.18$ & $3.90 \pm 1.08$ & 2.15 & 0.031 \\
\hline $\mathrm{FEV}_{1} / \mathrm{FVC}$ & $0.63 \pm 0.07$ & $0.8 I \pm 0.06$ & 99.81 & $<0.001$ \\
\hline $\begin{array}{l}\mathrm{FEV}, \% \\
\text { predicted* }\end{array}$ & $0.79 \pm 0.18$ & $0.98 \pm 0.14$ & 40.60 & $<0.001$ \\
\hline FVC\% predicted* & $0.96 \pm 0.17$ & $0.97 \pm 0.14$ & 2.33 & 0.020 \\
\hline EOS\%* & $3.16 \pm 2.21$ & $2.83 \pm 2.11$ & -5.79 & $<0.001$ \\
\hline NEU\%* & $\begin{array}{l}59.41 \\
\pm 9.26\end{array}$ & $57.52 \pm 9.37$ & -7.83 & $<0.001$ \\
\hline
\end{tabular}

Note: *There were some missing data in these baseline characteristics.

Metabolic syndrome (MS) was defined as a presence of 3 or more of the following 5 criteria: (1) abdominal obesity: waist circumference $\geq 102 \mathrm{~cm}$ for non-Hispanic white men, $\geq 88 \mathrm{~cm}$ for non-Hispanic white women, $\geq 94 \mathrm{~cm}$ for men of other races, and $\geq 80 \mathrm{~cm}$ for women of other races; (2) triglyceridemia $\geq 150 \mathrm{mg} / \mathrm{dL}$; (3) high-density lipoprotein cholesterol $<40 \mathrm{mg} / \mathrm{dL}$ for men and $<50 \mathrm{mg} / \mathrm{dL}$ for women; (4) $\mathrm{SBP} \geq 130 \mathrm{mmHg}, \mathrm{DBP} \geq 85 \mathrm{mmHg}$, or hypertension; and (5) fasting plasma glucose $\geq 100 \mathrm{mg} / \mathrm{dL}$ or DM. ${ }^{20}$

Dyslipidemia was defined as a presence of 1 or more of the following 4 criteria: (1) total cholesterol $\geq 240 \mathrm{mg} / \mathrm{dL}$; (2) triglyceridemia $\geq 150 \mathrm{mg} / \mathrm{dL}$; (3) low-density lipoprotein cholesterol $\geq 130 \mathrm{mg} / \mathrm{dL}$; and (4) high-density lipoprotein cholesterol $<40 \mathrm{mg} / \mathrm{dL}$ for men and $<50 \mathrm{mg} / \mathrm{dL}$ for women. ${ }^{21}$

Chronic kidney disease (CKD) was defined as an estimated glomerular filtration rate $<60 \mathrm{~mL} / \mathrm{min} / 1.73 \mathrm{~m}^{2}$, a urine albumin-creatinine ratio $\geq 30 \mathrm{mg} / \mathrm{g}$, or a self-reported physician diagnosis of CKD. The eGFR was calculated by the Chronic Kidney Disease Epidemiology Collaboration equation considering race, gender and creatinine. ${ }^{22,23}$

Anemia was defined as a hemoglobin $<13 \mathrm{~g} / \mathrm{dL}$ in men, an $\mathrm{Hb}<12 \mathrm{~g} / \mathrm{dL}$ in women, or a self-reported physician diagnosis of anemia. ${ }^{11}$

Osteoporosis was defined as T-score of lumbar region, total femur, or femoral neck $\leq-2.5$, Osteopenia was defined as $-2.5<\mathrm{T}$-score of lumbar region, total femur, 
or femoral neck $\leq-1$. T-score was calculated according to the equations of Looker et al considering bone mineral density and gender. ${ }^{24}$

Depression was defined according to the patient health questionnaire, which was a brief tool to assess the presence and severity of depressive symptoms (Supplementary Method). The severity of depression included none $(\leq 4)$, mild $(5 \sim 9)$, moderate $(10 \sim 14)$, moderately-severe $(15 \sim 19)$ and severe $(\geq 20){ }^{25}$

Arthritis, cancer (Supplementary Method), congestive heart failure $(\mathrm{CHF})$, coronary disease, stroke, asthma, chronic bronchitis and emphysema were diagnosis according to self-reported physician diagnosis.

\section{Statistical Analysis}

Clinical and demographic characteristics of subject with and without COPD were reported and compared using $t$-test for continuous variables and Chi-square test for categorical variable. Prevalence of 14 diseases in the COPD and nonCOPD populations were compared using Chi-square test. The associations between decrease of lung function indices and diseases were assessed using logistic regression model in COPD and non-COPD groups, respectively, with age, gender, race, BMI, education level, income level, smoking status, alcohol use, macronutrient intake (protein, carbohydrate, total fat), eosinophils percent (EOS\%), neutrophils percent (NEU\%), hypertension, DM and dyslipidemia as covariates. Calcium intake was also included as a covariate in the model for osteoporosis. $\mathrm{FEV}_{1} \%$ predicted and $\mathrm{FVC} \%$ predicted were analyzed as categorical variables in the logistic regression models, and the largest group was selected as reference group when the indices were analyzed as dummy variables. Cox proportional hazards model was used to evaluate the association between the reduced lung

Table 2 Prevalence of 14 Diseases in Subjects With and Without COPD

\begin{tabular}{|c|c|c|c|c|c|}
\hline Diseases & Entire Cohort & COPD & Non-COPD & $\chi^{2}$ & $P$ \\
\hline Hypertension & $5012(37.86)$ & 952 (52.89) & $4060(35.50)$ & 199.91 & $<0.001$ \\
\hline DM & $2092(15.80)$ & $386(21.44)$ & I 706 (I4.92) & 49.81 & $<0.001$ \\
\hline Dyslipidemia* & $8255(63.03)$ & II 197 (67.02) & $7058(62.40)$ & 14.11 & $<0.001$ \\
\hline MS & $3318(25.07)$ & $518(28.78)$ & $2800(24.48)$ & 15.28 & $<0.001$ \\
\hline $\mathrm{CHF}$ & $250(1.89)$ & $76(4.22)$ & $174(1.52)$ & 61.22 & $<0.001$ \\
\hline Coronary disease & $654(4.94)$ & $198(11.00)$ & 456 (3.99) & 162.86 & $<0.001$ \\
\hline Stroke & $302(2.28)$ & $75(4.17)$ & $227(1.98)$ & 33.21 & $<0.00$ I \\
\hline CKD & $1910(14.43)$ & $407(22.61)$ & $1503(13.14)$ & 112.95 & $<0.001$ \\
\hline Anemia & $1324(10.00)$ & $180(10.00)$ & II $44(10.00)$ & 0.00 & 1.000 \\
\hline Arthritis* & $3140(23.72)$ & 671 (37.28) & 2469 (21.59) & 211.53 & $<0.001$ \\
\hline Cancer & $998(7.54)$ & $275(15.28)$ & $723(6.32)$ & 178.96 & $<0.001$ \\
\hline \multicolumn{6}{|l|}{ Obesity* } \\
\hline Underweight & 183 (I.39) & $42(2.35)$ & I4I (I.24) & 78.42 & $<0.001$ \\
\hline Normal & $3664(27.82)$ & $594(33.24)$ & $3070(26.97)$ & & \\
\hline Overweight & $4417(33.53)$ & $637(35.65)$ & $3780(33.20)$ & & \\
\hline Obesity & $4908(37.26)$ & $514(28.76)$ & 4394 (38.59) & & \\
\hline \multicolumn{6}{|l|}{ Osteoporosis } \\
\hline Normal & $8093(6 I .14)$ & $899(49.94)$ & $7194(62.90)$ & 167.19 & $<0.001$ \\
\hline Osteopenia & $3403(25.7 I)$ & $508(28.22)$ & $2895(25.31)$ & & \\
\hline Osteoporosis & $174 \mid(13.15)$ & $393(21.83)$ & I348 (I I.79) & & \\
\hline \multicolumn{6}{|l|}{ Depression* } \\
\hline None & $934 \mid$ (76.52) & $1267(76.23)$ & $8074(76.56)$ & 7.53 & 0.110 \\
\hline Mild & $1815(14.87)$ & $263(15.82)$ & $1552(14.72)$ & & \\
\hline Moderate & $647(5.30)$ & $88(5.29)$ & $559(5.30)$ & & \\
\hline Moderately-Severe & $294(2.4 I)$ & $26(1.56)$ & $268(2.54)$ & & \\
\hline Severe & III (0.9I) & $18(1.08)$ & $93(0.88)$ & & \\
\hline
\end{tabular}

Note: *There were some missing data in these diseases. 
function and all-cause mortality after adjusting for the previous covariates asthma, emphysema, chronic bronchitis, and 14 extra-pulmonary diseases. All statistical analyses were performed using SAS 9.4 (SAS Institute Inc, Cary, North Carolina). $P$ values $<0.05$ were considered statistically significant.

\section{Results}

\section{Characteristics of the Study Population}

The demographic characteristics and lung function indices of COPD and non-COPD groups were presented in Table 1. Compared with the non-COPD population, COPD patients were more likely to be elder, men, non-Hispanic white and smoker, and had lower level of BMI, education, $\mathrm{FEV}_{1}$, $\mathrm{FVC}, \mathrm{FEV}_{1} / \mathrm{FVC}, \mathrm{FEV}_{1} \%$ predicted, $\mathrm{FVC} \%$ predicted, EOS\% and NEU\% $(P<0.05)$. Income level was not significantly different in 2 groups.

\section{Prevalence of Diseases in the COPD and Non-COPD Population}

Compared with the non-COPD population, COPD patients have a higher prevalence of hypertension, DM, dyslipidemia,
MS, CHF, coronary disease, stroke, CKD, arthritis, cancer, underweight and osteoporosis. Conversely, obesity was more common in the non-COPD population. There was no significant difference in the prevalence of anemia and depression between the 2 groups (Table 2 ).

\section{Association Between Decrease of Lung Function and Diseases}

In COPD patients, the decrease of $\mathrm{FEV}_{1} \%$ predicted and $\mathrm{FVC} \%$ predicted was significantly associated with higher odds of having hypertension, DM, obesity, MS, CHF, coronary disease and depression (odds ratio [OR] $>1$, $P<0.05$ ) after adjusting for a series of covariates (Figure 1). In the non-COPD population, the decrease of $\mathrm{FEV}_{1} \%$ predicted and $\mathrm{FVC} \%$ predicted were also related with higher odds of having 11 diseases after adjusting for a series of covariates, including hypertension, DM, obesity, dyslipidemia, MS, CHF, coronary disease, CKD, arthritis, osteoporosis and depression (Figure 2). The subgroup analysis for the non-COPD population showed that hypertension, obesity, CHF, coronary disease and depression were related with lung function in subjects aged $\geq 40$, arthritis and osteoporosis were related with lung function

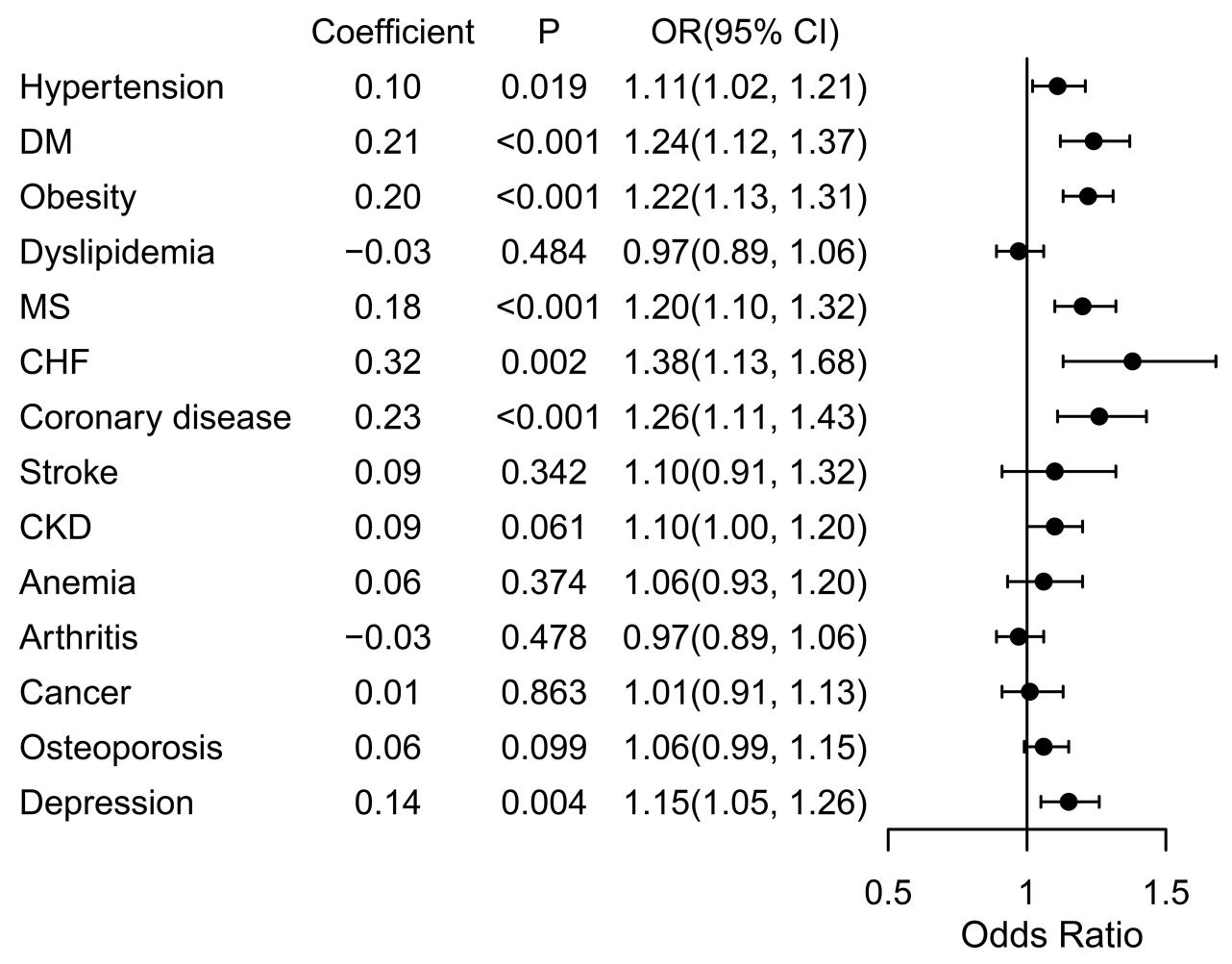

Figure I Associations between diseases and lung function in COPD patients after adjusting for multiple factors.

Notes: The following variables were removed from the logistic regression models to avoid collinearity because they are included in the definition of the corresponding diseases: MS: hypertension, DM, dyslipidemia; dyslipidemia: gender; obesity: BMI; CKD: gender, race; anemia: gender. 


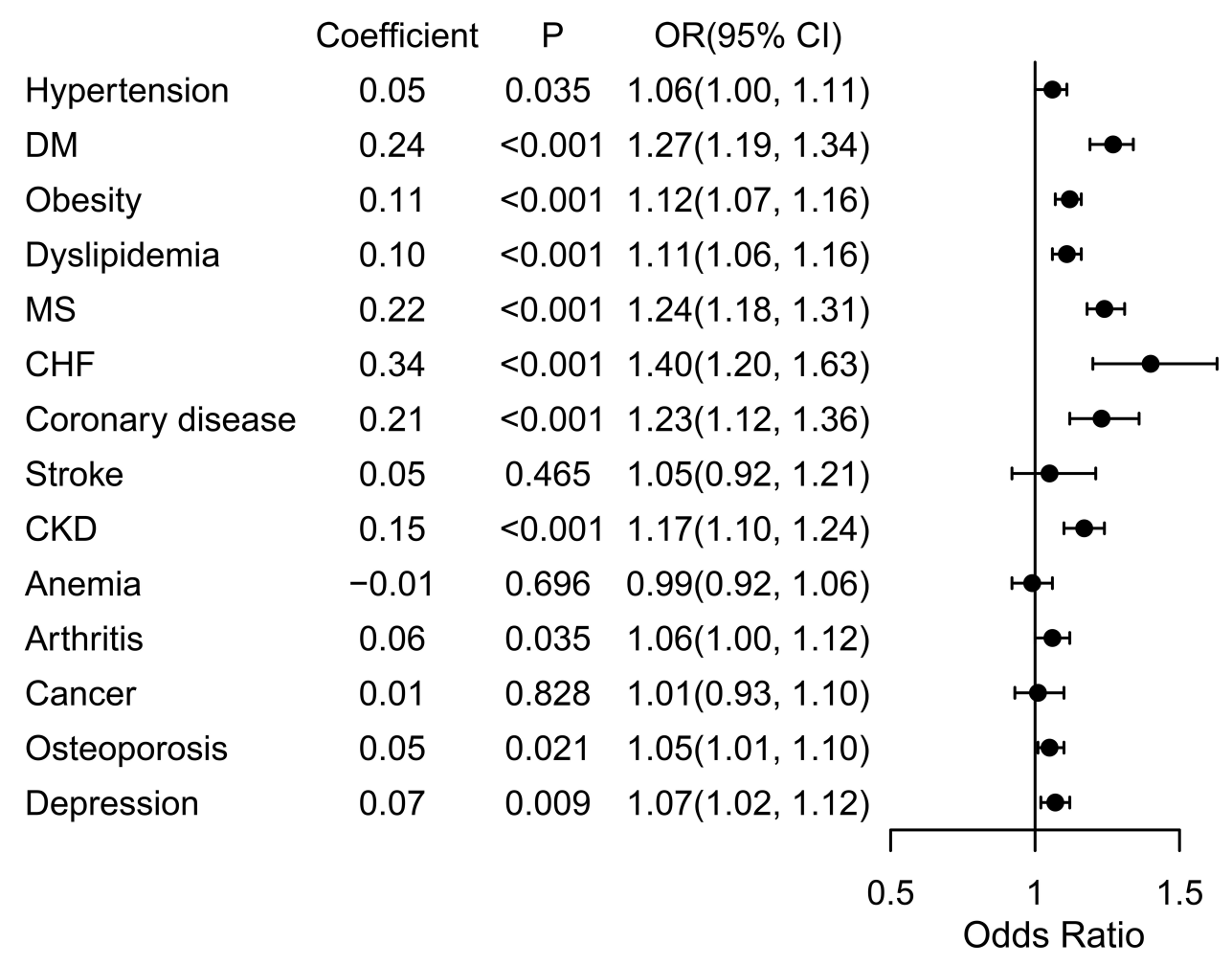

Figure 2 Associations between diseases and lung function in the non-COPD population after adjusting for multiple factors.

Notes: The following variables were removed from the logistic regression models to avoid collinearity because they are included in the definition of the corresponding diseases: MS: hypertension, DM, dyslipidemia; dyslipidemia: gender; obesity: BMI; CKD: gender, race; anemia: gender.

in subjects aged < 40, and DM, dyslipidemia, MS and CKD were related with lung function in both populations (Supplementary Figure 1).

By comparing subject groups of lower lung function with the largest quartile, we found that the odds of these diseases were gradually increased in both the COPD and non-COPD populations (Supplementary Figures 2-5).

\section{Association Between Decrease of Lung} Function and All-Cause Mortality

Association of the decrease of $\mathrm{FEV}_{1} \%$ predicted and $\mathrm{FVC}$ $\%$ predicted with all-cause mortality were presented in Table 3 and Supplementary Figure 6. As indicated by hazard ratio (HR) and $P$ value, subjects with lower $\mathrm{FEV}_{1}$ $\%$ predicted and $\mathrm{FVC} \%$ predicted had a higher risk of all-

Table 3 The Impact of Lung Function on All-Cause Mortality in the COPD and Non-COPD Population

\begin{tabular}{|c|c|c|c|c|c|c|c|}
\hline \multirow[t]{2}{*}{ Lung Function Indices } & & \multicolumn{3}{|c|}{ COPD } & \multicolumn{3}{|c|}{ Non-COPD } \\
\hline & & $\mathbf{b}$ & $P$ & HR $(95 \% \mathrm{Cl})$ & $\mathbf{b}$ & $\mathbf{P}$ & HR (95\% Cl) \\
\hline \multirow[t]{5}{*}{$\mathrm{FEV}_{1} \%$ predicted $^{\mathrm{a}}$} & 1 & 1.62 & $<0.001$ & $5.07(2.67,9.61)$ & 0.38 & 0.033 & $1.46(1.03,2.08)$ \\
\hline & 2 & 1.44 & $<0.001$ & $4.21(2.22,7.99)$ & 0.41 & 0.011 & I.5 (I.I, 2.06) \\
\hline & 3 & 0.8 & 0.016 & $2.23(1.16,4.3)$ & 0.18 & 0.236 & $\mathrm{I} .2(0.89, \mathrm{I} .6 \mathrm{I})$ \\
\hline & 4 & 1.08 & $<0.001$ & $2.96(1.57,5.56)$ & Ref & Ref & 1 \\
\hline & 5 & Ref & Ref & I & - & - & - \\
\hline \multirow[t]{4}{*}{ FVC\% predicted ${ }^{\mathrm{b}}$} & 1 & 0.93 & $<0.001$ & $2.52(1.55,4.09)$ & 0.44 & 0.014 & $1.56(I .1,2.22)$ \\
\hline & 2 & 0.72 & 0.003 & $2.06(1.28,3.32)$ & 0.44 & 0.006 & $1.56(1.14,2.13)$ \\
\hline & 3 & 0.26 & 0.332 & $1.3(0.77,2.19)$ & 0.32 & 0.039 & $1.37(1.02,1.86)$ \\
\hline & 4 & Ref & Ref & I & Ref & Ref & 1 \\
\hline
\end{tabular}

Notes: ${ }^{\mathrm{F} E \mathrm{~F}_{1}} \%$ predicted in the COPD population: $\mathrm{I}:<60 \%, 2: 60 \% \sim 70 \%, 3: 70 \% \sim 80 \%, 4: 80 \% \sim 90 \%, 5: \geq 90 \%$; $\mathrm{FEV}, \%$ predicted in the non-COPD population: $\mathrm{I}:<80 \%$, 2: $80 \% \sim 90 \%, 3: 90 \% \sim 100 \%, 4: \geq 100 \%$. ${ }^{\mathrm{F} F V C} \%$ predicted in the COPD and non-COPD populations: $1:<80 \%, 2: 80 \% \sim 90 \%, 3: 90 \% \sim 100 \%, 4: \geq 100 \%$. 
cause mortality after adjusting for the multiple covariates and all diseases.

\section{Discussion}

In this analysis, we found that the decrease of $\mathrm{FEV}_{1} \%$ predicted and $\mathrm{FVC} \%$ predicted were independent risk factors for hypertension, DM, obesity, MS, CHF, coronary disease and depression in both the COPD and non-COPD populations. Furthermore, these 2 indices were related with dyslipidemia, $\mathrm{CKD}$, arthritis and osteoporosis in the non-COPD population. In addition, the decrease of $\mathrm{FEV}_{1}$ $\%$ predicted and $\mathrm{FVC} \%$ predicted were independent risk factors for the increase of all-cause mortality. These risks were gradually increased with the decrease of lung function.

Some previous studies have reported the association of reduced lung function with extra-pulmonary diseases and mortality, mostly by comparing COPD patients with normal subjects. ${ }^{5-7,26-29}$ The population in NHANES has also been used in some studies. Navaneethan et al reported patients with CKD had higher odds of COPD using NHANES 2007-2012. ${ }^{5}$ The relation between decrease of lung function and MS has been reported using NHANES III (1988-1994) and NHANES 2007-2010. ${ }^{27,28}$ Here, we also found the similar increased prevalence of comorbidities and mortality in COPD patients using NHANES 2007-2012. In contrast to the previous studies focused on COPD patients, the key finding of this study was that the decrease of lung function was also independent risk factor for some extra-pulmonary diseases and mortality in the non-COPD population.

The associations in our study may not be a causal relationship between the decrease of lung function and extra-pulmonary diseases. There are several plausible explanations for these associations. The decrease of lung function and diseases may share same risk factors, such as smoking, age, obesity, hypertension, nutritional status and systemic inflammation. ${ }^{30,31}$ These factors may lead to the structural changes in both lung tissue and other biological systems, which will lead to reduced lung function, various diseases and increase of mortality. ${ }^{32}$ However, the associations of reduced lung function and these diseases still remained statistically significant even after adjusting for these possible confounders. Systemic hypoxia caused by the decrease of lung function may also contribute to cell damage and systemic inflammatory reactions, which will further lead to multiple diseases. ${ }^{33}$
The decrease of lung function tended to have stronger associations with diseases and all-cause mortality among the COPD population than the non-COPD population. COPD can increase the mortality of population caused by other diseases, such as heart disease and cancer in this study. In the non-COPD population, the HR values were smaller than that of the COPD population. The possible reasons may be that COPD patients had poorer global health status, and the impact of reduced lung function on systemic hypoxia and the adverse effects were more severe in these patients. ${ }^{33-35}$

The present study has several limitations. First, the diagnosis of COPD was based on pre-bronchodilator spirometry test due to the lack of post-bronchodilator spirometry test, which may misdiagnose patients with reversible obstructive lung function as COPD patients, and overestimate the prevalence of COPD. Second, some subjects were excluded from the spirometry test, such as patients with recent chest pain, heart attack, stroke, surgery of eye, chest, or abdomen, and history of collapsed lung, aneurysm, or detached retina, which may exclude subjects with reduced lung function and lead to some biases in the results. Third, this was a crosssectional study, which was unable to establish causal relationships between lung function and diseases and all-cause mortality. Finally, some unmeasured confounding could not be adjusted in the logistic and Cox models.

\section{Conclusion}

In conclusion, the decrease of $\mathrm{FEV}_{1} \%$ predicted and $\mathrm{FVC}$ $\%$ predicted were related with higher risk of multiple diseases and all-cause mortality in both the COPD and non-COPD population, mainly including hypertension, DM, obesity, dyslipidemia, MS, CHF, coronary disease, CKD, arthritis, osteoporosis and depression. Most of these relations tended to be weaker in the non-COPD population compared with the COPD population when the results were statistically significant in the COPD population. The risk of stroke, anemia, and cancer was not related with the decrease of lung function.

\section{Abbreviations}

COPD, chronic obstructive pulmonary disease; FEV1\% predicted, Forced expiratory volume in 1 second percent of predicted; FVC\% predicted, forced vital capacity percent of predicted; DM, diabetes mellitus; NHANES, National Health and Nutrition Examination Survey; CDC, Centers for Disease Control and Prevention; SBP, systolic blood pressure; DBP, diastolic blood pressure; BMI, body mass index; MS, Metabolic syndrome; CKD, Chronic kidney 
disease; CHF, congestive heart failure; EOS $\%$, eosinophils percent; NEU\%, neutrophils percent.

\section{Funding}

This study was supported by the National Natural Science Foundation of China (Grant number: 81703322).

\section{Disclosure}

The authors report no conflicts of interest in this work.

\section{References}

1. Petousi N, Talbot NP, Pavord I, Robbins PA. Measuring lung function in airways diseases: current and emerging techniques. Thorax. 2019;74(8):797-805. doi:10.1136/thoraxjnl-2018-212441

2. Graham BL, Steenbruggen I, Miller MR, et al. Standardization of spirometry 2019 update. An official American Thoracic Society and European Respiratory Society technical statement. Am J Respir Crit Care Med. 2019;200(8):e70-e88. doi:10.1164/rccm.201908-1590ST

3. Singh D, Agusti A, Anzueto A, et al. Global strategy for the diagnosis, management, and prevention of chronic obstructive lung disease: the GOLD science committee report 2019. Eur Respir J. 2019;53(5):1900164. doi:10.1183/13993003.00164-2019

4. Chan SMH, Selemidis S, Bozinovski S, Vlahos R. Pathobiological mechanisms underlying metabolic syndrome (MetS) in chronic obstructive pulmonary disease (COPD): clinical significance and therapeutic strategies. Pharmacol Ther. 2019;198:160-188. doi:10.1016/jharmthera.2019.02.013

5. Navaneethan SD, Mandayam S, Arrigain S, Rahman M, Winkelmayer WC, Schold JD. Obstructive and restrictive lung function measures and CKD: National Health and Nutrition Examination Survey (NHANES) 2007-2012. Am J Kidney Dis. 2016;68 (3):414-421. doi:10.1053/jjkd.2016.03.415

6. Onishi K. Total management of chronic obstructive pulmonary disease (COPD) as an independent risk factor for cardiovascular disease. J Cardiol. 2017;70(2):128-134. doi:10.1016/jjcc.2017.03.001

7. Gershon A, Hwee J, Victor JC, et al. Mortality trends in women and men with COPD in Ontario, Canada, 1996-2012. Thorax. 2015;70 (2):121-126. doi:10.1136/thoraxjnl-2014-205956

8. Gershon AS, Thiruchelvam D, Chapman KR, et al. Health services burden of undiagnosed and overdiagnosed COPD. Chest. 2018;153 (6):1336-1346. doi:10.1016/jhest.2018.01.038

9. Chai C-S, Liam C-K, Pang Y-K, et al. $<\mathrm{p}>$ Clinical phenotypes of COPD and health-related quality of life: a cross-sectional study. Int J Chron Obstruct Pulmon Dis. 2019;14:565-573. doi:10.2147/ COPD196109

10. Lee H, Shin SH, Gu S, et al. Racial differences in comorbidity profile among patients with chronic obstructive pulmonary disease. $B M C$ Med. 2018;16(1):178. doi:10.1186/s12916-018-1159-7

11. Jo YS, Choi SM, Lee J, et al. The relationship between chronic obstructive pulmonary disease and comorbidities: a cross-sectional study using data from KNHANES 2010-2012. Respir Med. 2015;109 (1):96-104. doi:10.1016/jmed.2014.10.015

12. Tantucci C, Modina D. Lung function decline in COPD. Int J Chron Obstruct Pulmon Dis. 2012;7:95-99. doi:10.2147/COPD27480

13. Nathell L, Nathell M, Malmberg P, Larsson K. COPD diagnosis related to different guidelines and spirometry techniques. Respir Res. 2007;8(1):89. doi:10.1186/1465-9921-8-89

14. Hall GL, Irvin CG. Using lung function measurements to greater advantage in patients with lung disease: which test and when? Respirology (Carlton, Vic). 2014;19(6):780-781. doi:10.1111/ resp. 12331
15. Kodal JB, Kobylecki CJ, Vedel-Krogh S, Nordestgaard BG, Bojesen SE. AHRR hypomethylation, lung function, lung function decline and respiratory symptoms. Eur Respir J. 2018;51(3):3. doi:10.1183/13993003.01512-2017

16. Hankinson JL, Odencrantz JR, Fedan KB. Spirometric reference values from a sample of the general U. population. Am J Respir Crit Care Med. 1999;159(1):179-187. doi:10.1164/ajrccm.159.1.9 712108

17. Bakris G, Ali W, Parati G. ACC/AHA versus ESC/ESH on hypertension guidelines: JACC guideline comparison. $J$ Am Coll Cardiol. 2019;73(23):3018-3026. doi:10.1016/jacc.2019.03.507

18. Association AD. 2. Classification and diagnosis of diabetes: standards of medical care in diabetes-2018. Diabetes Care. 2018;41(Suppl 1): S13-S27. doi:10.2337/dc18-S002

19. Ward ZJ, Bleich SN, Cradock AL, et al. Projected US state-level prevalence of adult obesity and severe obesity. $N$ Engl $J$ Med. 2019;381(25):2440-2450. doi:10.1056/NEJMsa1909301

20. Alberti KG, Eckel RH, Grundy SM, et al. Harmonizing the metabolic syndrome: a joint interim statement of the International Diabetes Federation Task Force on Epidemiology and Prevention; National Heart, Lung, and Blood Institute; American Heart Association; World Heart Federation; International Atherosclerosis Society; and International Association for the Study of Obesity. Circulation. 2009;120(16):1640-1645. doi:10.1161/CIRCULATIONAHA.109.19 2644

21. Park HJ, Leem AY, Lee SH, et al. Comorbidities in obstructive lung disease in Korea: data from the fourth and fifth Korean National Health and Nutrition Examination Survey. Int J Chron Obstruct Pulmon Dis. 2015;10:1571-1582. doi:10.2147/COPD85767

22. Levey AS, Stevens LA, Schmid $\mathrm{CH}$, et al. A new equation to estimate glomerular filtration rate. Ann Intern Med. 2009;150 (9):604-612. doi:10.7326/0003-4819-150-9-200905050-00006

23. Stevens PE, Levin A. Evaluation and management of chronic kidney disease: synopsis of the kidney disease: improving global outcomes 2012 clinical practice guideline. Ann Intern Med. 2013;158 (11):825-830. doi:10.7326/0003-4819-158-11-201306040-00007

24. Looker AC. Femur neck bone mineral density and fracture risk by age, sex, and race or Hispanic origin in older US adults from NHANES III. Arch Osteoporos. 2013;8:141. doi:10.1007/s11657013-0141-4

25. Kroenke K, Spitzer RL, Williams JB. The PHQ-9 validity of a brief depression severity measure. J Gen Intern Med. 2001;16(9):606-613. doi:10.1046/j.1525-1497.2001.016009606

26. Raherison C, Ouaalaya EH, Bernady A, et al. Comorbidities and COPD severity in a clinic-based cohort. BMC Pulm Med. 2018;18 (1):117. doi:10.1186/s12890-018-0684-7

27. Chen WL, Wang CC, Wu LW, et al. Relationship between lung function and metabolic syndrome. PLoS One. 2014;9(10):e108989. doi:10.1371/journalone.0108989

28. Ford ES, Cunningham TJ, Mercado CI. Lung function and metabolic syndrome: findings of National Health and Nutrition Examination Survey 2007-2010. J Diabetes. 2014;6(6):603-613. doi:10.1111/ $1753-0407.12136$

29. Wheaton AG, Ford ES, Thompson WW, Greenlund KJ, PresleyCantrell LR, Croft JB. Pulmonary function, chronic respiratory symptoms, and health-related quality of life among adults in the United States-National Health and Nutrition Examination Survey 2007-2010. BMC Public Health. 2013;13(1):854. doi:10.1186/14712458-13-854

30. Fabbri LM, Luppi F, Beghé B, Rabe KF. Complex chronic comorbidities of COPD. Eur Respir J. 2008;31(1):204-212. doi:10.1183/ 09031936.00114307

31. Zhang J, Ou JX, Bai CX. Tobacco smoking in China: prevalence, disease burden, challenges and future strategies. Respirology (Carlton, Vic). 2011;16(8):1165-1172. doi:10.1111/j.1440-1843.20 11.02062 
32. Niles AN, O’Donovan A. Comparing anxiety and depression to obesity and smoking as predictors of major medical illnesses and somatic symptoms. Health Psychol. 2019;38(2):172-181. doi:10.1037/hea0000707

33. Kent BD, Mitchell PD, McNicholas WT. Hypoxemia in patients with COPD: cause, effects, and disease progression. Int J Chron Obstruct Pulmon Dis. 2011;6:199-208. doi:10.2147/COPD10611
34. Agustí AG. Systemic effects of chronic obstructive pulmonary disease. Proc Am Thorac Soc. 2005;2(4):367-370; discussion 371362. doi:10.1513/pats.200504-026SR

35. Tuder RM, Yun JH, Bhunia A, Fijalkowska I. Hypoxia and chronic lung disease. J Mol Med (Berl). 2007;85(12):1317-1324. doi:10.1007/s00109-007-0280-4

\section{Publish your work in this journal}

Clinical Epidemiology is an international, peer-reviewed, open access, online journal focusing on disease and drug epidemiology, identification of risk factors and screening procedures to develop optimal preventative initiatives and programs. Specific topics include: diagnosis, prognosis, treatment, screening, prevention, risk factor modification,

Submit your manuscript here: https://www.dovepress.com/clinical-epidemiology-journal systematic reviews, risk \& safety of medical interventions, epidemiology \& biostatistical methods, and evaluation of guidelines, translational medicine, health policies \& economic evaluations. The manuscript management system is completely online and includes a very quick and fair peer-review system, which is all easy to use. 